\title{
A NOVEL SEED BAITING TECHNIQUE FOR THE EPIPHYTIC ORCHID RHYNCHOSTELE CERVANTESII, A MEANS TO ACQUIRE MYCORRHIZAL FUNGI FROM PROTOCORMS
}

\author{
Jesús Bernardo Cruz-Higareda ${ }^{1,2}$, Bárbara Susana Luna-Rosales ${ }^{1}$ \\ \& AMADEO BARBA- Álvarez ${ }^{1}$ \\ ${ }^{1}$ Unidad de Investigación en Biología Vegetal (L-301), Facultad de Estudios Superiores Zaragoza Campo II, \\ Universidad Nacional Autónoma de México, AP 0920, México, D.F., CP 09230, México \\ ${ }^{2}$ Author for coorespondece: bdocruzh@gmail.com
}

\begin{abstract}
We developed a new and novel seed baiting technique sowing mature seeds of the epiphyitic orchid Rhynchostele cervantesii under natural conditions, We introduced a sponge in each package that may serve as a reservoir for water retention to benefit germination; In three of 22 packets we found protocorms in an early stage of development, six of wich were of sufficient size to warrant fungal isolations; Nine strains were isolated in pure culture and were inoculated on seeds and protocorms under in vitro conditions.
\end{abstract}

KEY words: Orchid, Epiphytic, Seed, Baiting, Mycorrhiza, Rhynchostele

Introduction. In nature, orchids utilize mycorrhizal fungi as a carbon source (mycotrophy) to facilitate seed germination and seedling development, and many are thought to remain intimately tied to fungi into maturity. Although most (73\%) the world's 17,00035,000 orchid species exist as tropical epiphytes (Atwood 1986; Cribb et al. 2003), surprisingly few taxa have been studied with respect to their mycorrhizal associations compared to their temperate terrestrial counterparts. During the last decade, however, a growing number of studies have been published that document mycorrhizal fungi from tropical orchids worldwide including Brazil (e.g., Pereira et al. 2003, 2005), China (e.g., Chen et al. 2012), Ecuador (Suárez et al. 2006), Puerto Rico (Otero et al. 2007), and Thailand (e.g., Nontachaiyapoom et al. 2010) among other places. This information comes at a critical time for specialists seeking knowledge of mycorrhizal fungi for conservation purposes (e.g., symbiotic seed germination), but a great deal still must be learned about this aspect of orchid biology before effective protocols can be developed.

The difficulty faced by most researchers who aspire to study mycorrhizal associations of orchids in situ lies in the extremely small dust-like size of the orchid seed itself which is nearly impossible to observe on natural substrates with the unaided eye. For epiphytic orchids, researchers are faced with an additional burden of having to ascend into the tree canopy for long periods of time. The seed baiting technique initially developed by Rasmussen and Whigham (1993) has helped considerably with the former, resulting in more than a hundred studies carried out in situ during the past 20 years, mostly involving terrestrial orchids (Rasmussen, 2002). For epiphytic orchids, a modified seed baiting technique has since been developed that emphasizes affixing seed packets to arboreal substrates (Zettler et al. 2011; Zi et al. 2014) which may have potentials for use in a wide range of taxa. Nevertheless, seeds in packets that are attached to aerial substrates are highly vulnerable to desiccation, even in packets placed in direct contact with (moist) moss in continuous shade. Zettler et al. (2011) reported that only one of 60 seed packets affixed to trees harbored protocorms of Epidendrum amphistomum in south Florida, for example, and they proposed that moisture-rich substrates were needed for fungal growth and proliferation to trigger epiphytic orchid seed germination. If true, it is conceivable that placing a water absorbing/retaining material within the seed packet itself may raise moisture to levels conducive to germination. This possibility was the focus of our study.

In this paper, we propose a novel technique for enhancing epiphytic orchid seed germination in situ using seed packets containing mature seeds of a threatened species endemic to Mexico, Rhynchostele cervantesii (Fig. 1). 


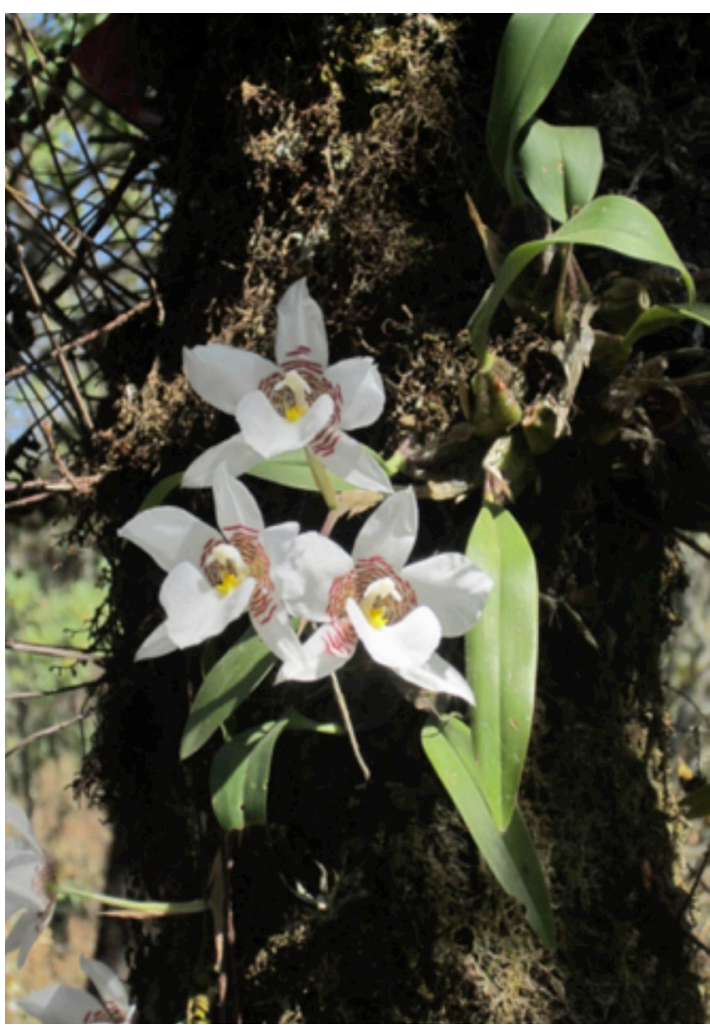

FIGURE 1. Photography of Rhynchostele cervantesii taken on study site.

Material and Methods. Development of the Seed Baiting Technique -. Seeds of Rhynchostele cervantesii (La Llave \& Lex.) were obtained from mature capsules in the act of dehiscing during February of 2011 and March of 2012, from three individual plants within a natural population in "El Tepozteco" National Park (vicinity of Tepoztlán, in the state of Morelos). The seeds of each capsule were added to sealed, sterile glass vials containing desiccant (CaSO4, Baker ${ }^{\circledR}$ Chemical Co.) and stored at $4{ }^{\circ} \mathrm{C}$ in darkness. Seed viability was assessed using a $1 \%$ solution of triphenyltetrazolium chloride (TTC). The TTC solution was prepared by dissolving $1 \mathrm{~g}$ of 2,3,5-triphenyltetrazolium chloride in $100 \mathrm{ml}$ of sterile deionised (DI) water. Seeds were then pre-treated in small flasks (vials) containing $20 \mathrm{ml}$ of a $5 \% \mathrm{NaOCl}+$ $1 \%$ solution for $5 \mathrm{~min}$. Following pre-treatment, seeds were rinsed then allowed to soak in $10 \mathrm{ml}$ DI water, and were then transferred to $1 \%$ TTC solution $(10 \mathrm{ml})$ for $72 \mathrm{hrs}$ at $30^{\circ} \mathrm{C}$ in darkness. Seeds were examined under a stereomicroscope and scored as viable (pink or red embryo) or unviable (unstained embryo) as described by Van Waes and Debergh (1986).

Packets were constructed from $10 \times 5 \mathrm{~cm}$ rectangles of plankton netting mesh with pore size of 65 $\mu \mathrm{m}$ purchased from (Medios Industriales Filtrantes S.A de C.V. San Andres Atoto St. No 75, Nauclapan de Juárez) (Fig. 2). The netting was folded in half and sealed on two of the three sides using a hot glue gun purchased from a local hobby store (Surtek ${ }^{\circledR}$ model PS611). The glue used consisted of stick hot melt glue ( $25 \mathrm{~cm}$ in length and $7 \mathrm{~mm}$ in diameter, Surtek ${ }^{\circledR}$ Perillar AV. $\mathrm{N}^{\circ} 99$ Méx. ) that is considered non-toxic, and the above process resulted in $5 \times 5 \mathrm{~cm}$ packets (Fig. 3 ). Using a scalpel, $3.5 \times 2.5 \times 0.5 \mathrm{~cm}$ rectangles of a synthetic sponge (Polyurethane foam, Fischermex ${ }^{\circledR}$ Avila Camacho Blvd. N 3130 Tlalnepantla Mex.) were constructed (Fig. 4), and both packets and sponge pieces were then rinsed in tap water to strip any chemical residue that may be present. The packets and sponges were then disinfested in a solution of $\mathrm{NaOCl}(0.5 \% \mathrm{v} / \mathrm{v})$ for 10 min., subsequently rinsed with sterile DI water, and were allowed to dry at ambient temperature. Once dry, ca. 7,000-7,500 seeds (100 mg) were homogeneously dispersed over the sponge (Fig. 5) after it was placed into a nylon mesh packet (Fig. 6). The third edge of the packet was then sealed shut assisted by the hot glue gun (Fig. 7). A total of 22 packets were constructed in this manner.

Seed Packet Installation and Retrieval -. A total of 22 host trees (phorophytes) were selected for seed packet placement. Each tree harbored at least one seemingly-healthy specimen of $R$. cervantesii, and these phorophytes were identified as: Quercus rugosa Neé (1801). Each packet was placed at a height of 1-30 $\mathrm{m}$ from the ground on a branch that harbored young orchid specimens (ca. $1.5 \mathrm{~cm}$ in height, with pseudobulbs and leaves). All packets were placed in close proximity (ca. $5 \mathrm{~cm}$ ) of a young orchid (Fig. 8), and affixed to the branch by means of an elastic nylon thread. Each packet was then lightly covered with lichen and/or moss colonies from the same tree branch to mimic natural environmental conditions. Half (11) of the packets were placed in situ 1-3 months after seeds were collected (March-May on 2011 ), and other 11 packets were outplanted one year later (2012) (seed used were always of the same year they were col- 


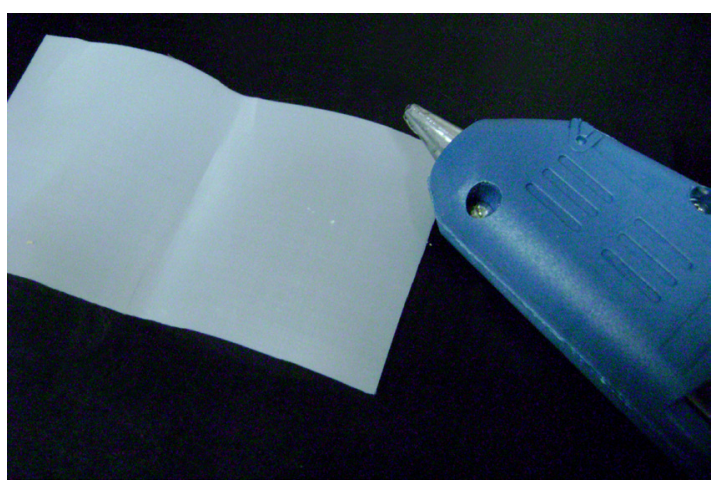

FIGURE 2. Rectangles of plankton netting mesh.

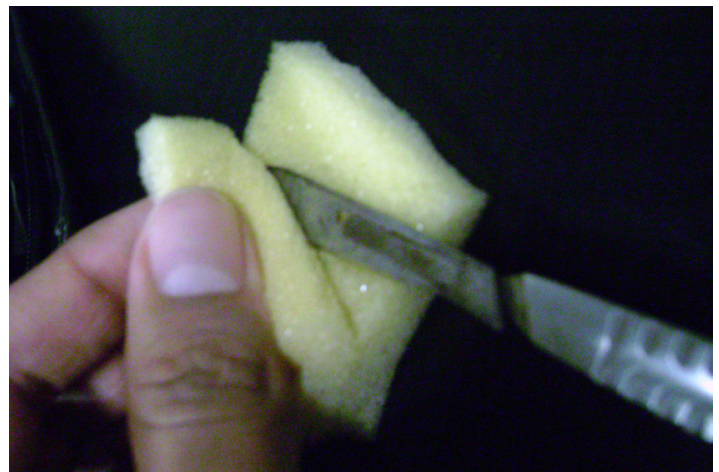

FIGURE 4. Construction of synthetic sponge rectangles.

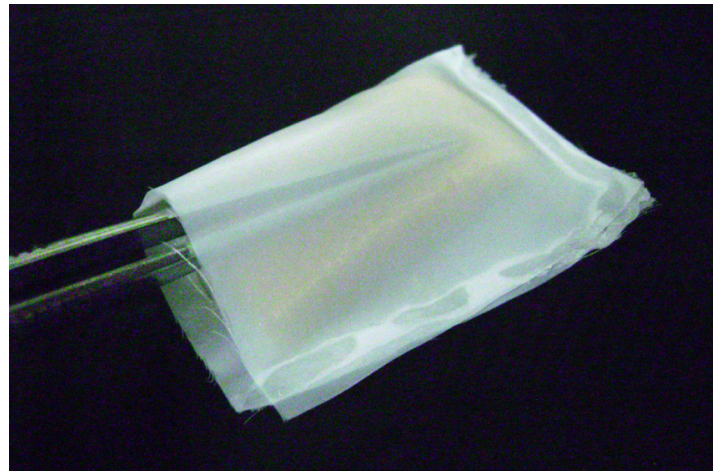

FiguRE 6. The sponge whit seeds was placed into a nylon mesh packet.

lected, this is because the stored seeds lose their viability after six months)- Each packet was assigned a reference number and the following parameters were recorded: UTM coordinates with a GPS to georeference each phorophyte, orientation (north, south, east, west), height above the ground, location on the phorophyte (trunk, branch or fork), associated organisms

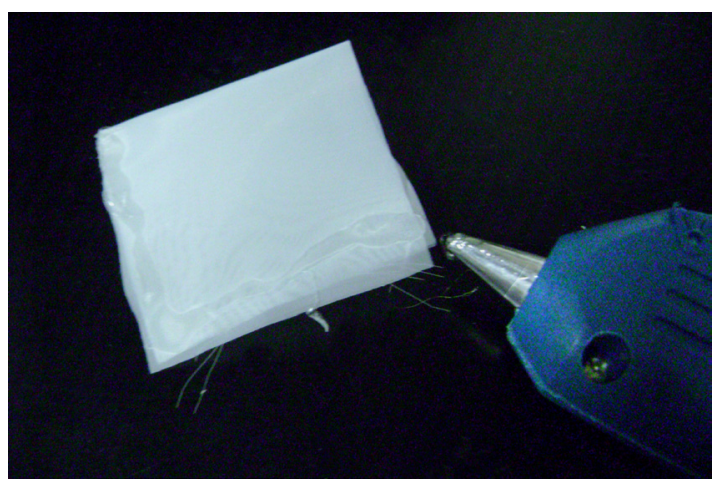

Figure 3. Plankton netting mesh was folded and sealed to create a single packet.

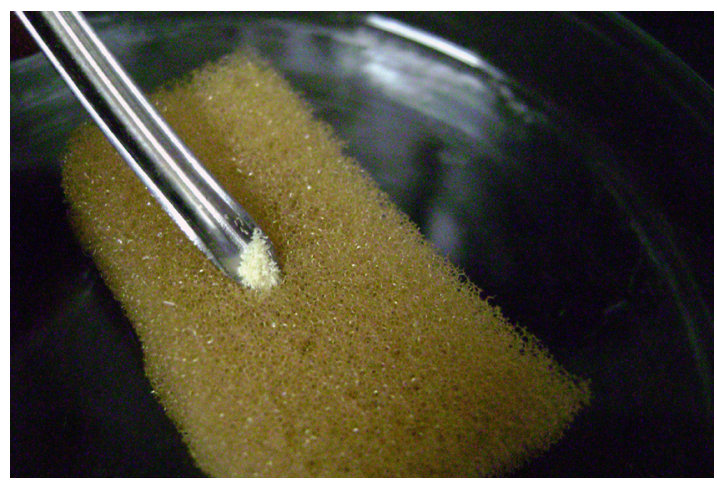

FigURE 5. Seeds was dispersed on the surface of the sponge.

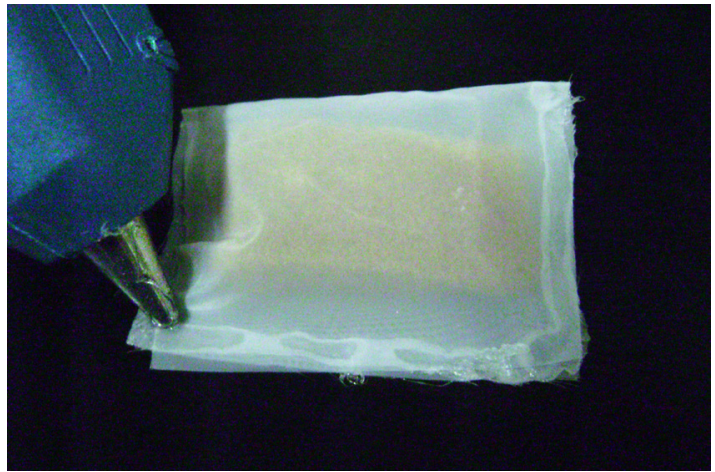

FIGURE 7. The packet was finally sealed.

(lichens, mosses, ferns, bromeliads, etc.). All packets remained in the field 3-5 months, after which time the packets were collected. Care was taken to detach packets along with associated substrate (bark, moss, lichens) which were added to separate sterile containers that were sealed to retain moisture. Containers were placed into an insulated ice cooler (lacking ice) for 


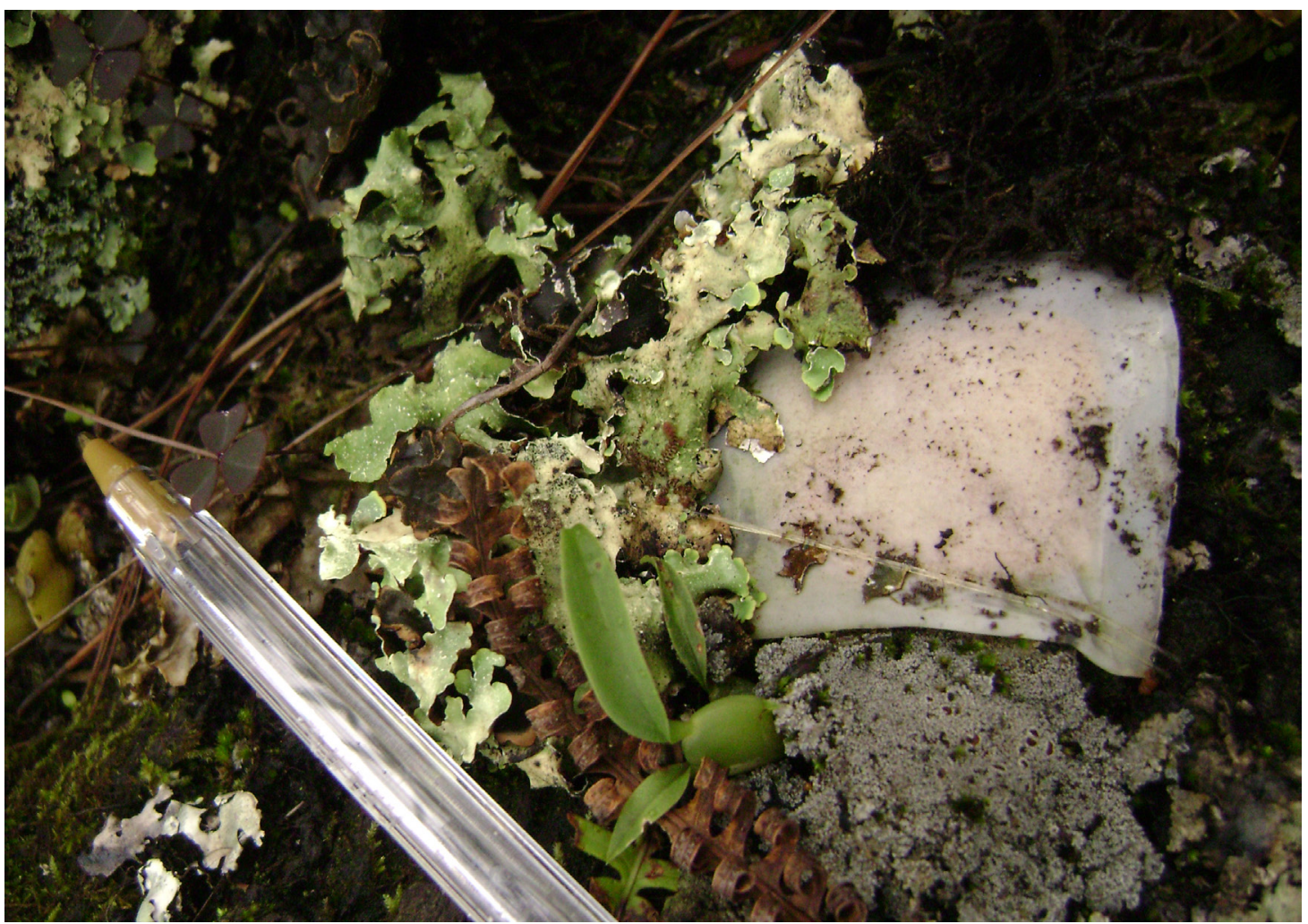

Figure 8. One of the 22 baits installed in situ.

transport to the laboratory $24-48$ hrs later. Packets and sponges were initially inspected in the laboratory using a dissection microscope, and those that appeared to contain seeds in the act of germinating were placed on microscope slides for additional observations using a compound microscope fitted with a camera.

Fungal isolation and symbiotic seed germination -. Protocorms (3 to $5 \mathrm{~mm}$ in diameter) were carefully removed from the sponge whit sterile forceps measured and placed in individual sterile glass vials containing sterile distilled water and vigorously shaken to remove debris and surface contaminants (rinse five times according to (Bonnardeaux et al., 2007). Protocorms were then removed from the distilled water using a sterile pipette and surface sterilized $1 \mathrm{~mm}$ in another glass vial containing $5 \mathrm{ml}$ of absolute ethanol (EtOH) for three minutes; $25 \% \mathrm{NaOCl}$ (Clorox bleach) and 900 $\mathrm{ml}$ of distilled water for 10 minutes. Protocorms were removed from the solution and rinsed twice for $1 \mathrm{~mm}$ each in sterile DI water in a third vial each protocorm was then placed in its own sterile plastic Petri plate. Each protocorm was dissected with a sterile scalpel and each segment plated onto nutrient agar culture media used for fungal isolations (FIM, Angle et al., 1991). Hyphal tips originating from pelotons that were clearly visible under a dissection microscope were excised using a sterile scalpel. Pure cultures were obtained by removing a single hyphal tip from FIM to FIM or Potato dextrose agar (Bioxon Becton Dickinson ${ }^{\circledR}$ ). Colony growth was observed during a three week period, and cultural characteristics (hyphal growth rate, width, cell appereance) similar to protocol outlined by Currah et al., (1990). Seeds were removed from cold storage (4 $\left.{ }^{\circ} \mathrm{C}\right)$ surface disinfected as reported previously for protocorms, between 100-600 seeds were placed over the surface of a filter paper strip (Whatman No. 40) on the surface of oat medium agar (OMA) (3.5 g rolled oats, $0.1 \mathrm{~g}$ yeast extract, $6.0 \mathrm{~g}$ agar, $1 \mathrm{~L}$ DI water) whitin a Petri plate. A $0.5 \mathrm{~cm} 3$ block of fungal inoculums was added to one side of the paper strip, and each plate was immediately wrapped in Parafilm to retain mois- 
ture and minimize contamination. Plates were then wrapped tightly in aluminum foil to exclude light, and incubated at $22^{\circ} \mathrm{C}$ for 13 weeks (three replicate plates were prepared per fungus). We sown seeds on $\mathrm{Mu}-$ rashige and Skoog medium (MS) with [50\%] of basal salts, supplemented with sucrose and agar (Sigma ${ }^{\circledR}$ Aldrich Co.). After three months, spherical protocorms (5-7 mm of diameter) with apical shoots were developed, 15 of these protocorms were placed on Petri dish with OMA by adding a bucket with fungal hyphae agar for inoculation in vitro (three replicate plates were prepared per fungus and protocorms were incubated at $22^{\circ} \mathrm{C}$ in a photoperiod of 16 hours light and 8 hours dark, with a light intensity of 322.9 lux, for 15 weeks)

Results and Discussion. The seed baiting method presented here improved on previous techniques in the following: flexibility for closer contact with natural substrates and increased water retention using pieces of sponge. These modifications showed distinct advantages. First, replacing the rigid frame by a flexible frame made with hot glue made the placement of the baits on the trunks, forks or branches easier and allowed for better mimicking of the natural conditions. It is often difficult to place the rigid frames of previously used techniques to close contact with the surface of phorophyte and, therefore, seeds often lose their viability or do not become infected by the fungal symbionts. In our improved seed baiting technique, the sponge mimics the water retention capacity of the mosses so the seeds do not lose moisture as quickly, raising the possibility of priming the mycorrhizal fungus. Yoder et al. (2000) establishes that the seeds of the epiphytes are able to absorb water from the air, this capacity suggests that these seeds are able to acquire the rainwater in a very porous substrate (the sponge provides an aerated substrate). Three of the 22 seed packets harbored developing protocorms of $R$. cervantesii after 124 days of incubation in situ on tree trunks, especially those with $80-90 \%$ moss coverage. In one particular packet ( $\mathrm{RC} 08)$, four protocorms were observed, and in the other two packets (RC06, RC07), seeds appeared to be in the process of germinating (Fig. 9). In two of the protocorms (Fig. $9 \mathrm{E}$ and $\mathrm{F}$ ), dark spherical inclusions were apparent that resembled fungal pelotons in epiphytic orchid protocorms published previously (e.g. Zettler et al. 1999). The fact is that these packages were collected during the months in which the fog and the rainfall was evident in the study area. According to some authors seasonal patterns in orchid fungal symbionts are closely related to host phenology and climate variations; and the overall picture shows that the diversity of fungi associated with orchids and the frequency and intensity of colonization in the roots increase in the wet months, while many of these fungi remain dormant as spores during dry seasons (Lugo \& Cabello, 2002; Dumbrell et al., 2010). During the sampling seasons, packets were colonized by lichens and mosses present on the phorophyte, and formed a dense rug of about $5 \mathrm{~cm}$ thick on the surface, with an accumulating layer of decomposing organic matter. Many lichens and mosses can fix atmospheric nitrogen via their symbiotic cyanobacteria of the genus ( e.g. the genus Nostoc) mosses can absorb leached-out nutrients from runoff water (Rai et al., 2000; DeLuca et al., 2002). It is likely that the sponge contained in the packets can absorb runoff in a similar matter, facilitating germination and fungal colonization. So it is not surprising that some authors suggest that mosses retain much of the nitrogen after death and during decomposition (Turetsky, 2003; Clarck et al., 1998; 2005). The fact is that lichens and particularly mosses are authentic recalcitrant stores of carbon and nitrogen whose concentrations are higher in epiphytic than in terrestrial bryophytes and that when they die, they produce humus whit nutrients that are highly soluble in water, being a dominant mass of carbon and nitrogen which is involved in the cycle of nutrients to flow through the canopy to the ground via runoff (Chia-Chun et al., 2002; Turetsky, 2003; Clarck et al., 2005, Cornelissen et al., 2007) For future works, we recommend install the packets (or plantlets generated in vitro for purposes of reintroduction) on moss substrate on the surface of the phorophyte; Also we observed that the phorophytes (Quercus rugosa) had developed a layer of bark (about 3-5 cm thick) underneath the moss colonies. Rasmussen \& Wigham (1988 a) reported that the debris of certain species of trees can stimulate germination of orchid seeds, and is also suitable substrate for inducing subsequent mycorrhizal seedling development, suggesting that indeed the fungi involved are saprophytic.

Nine strains with different morphology were successfully isolated from six protocorms and inoculated on seeds and protocorms generated under 


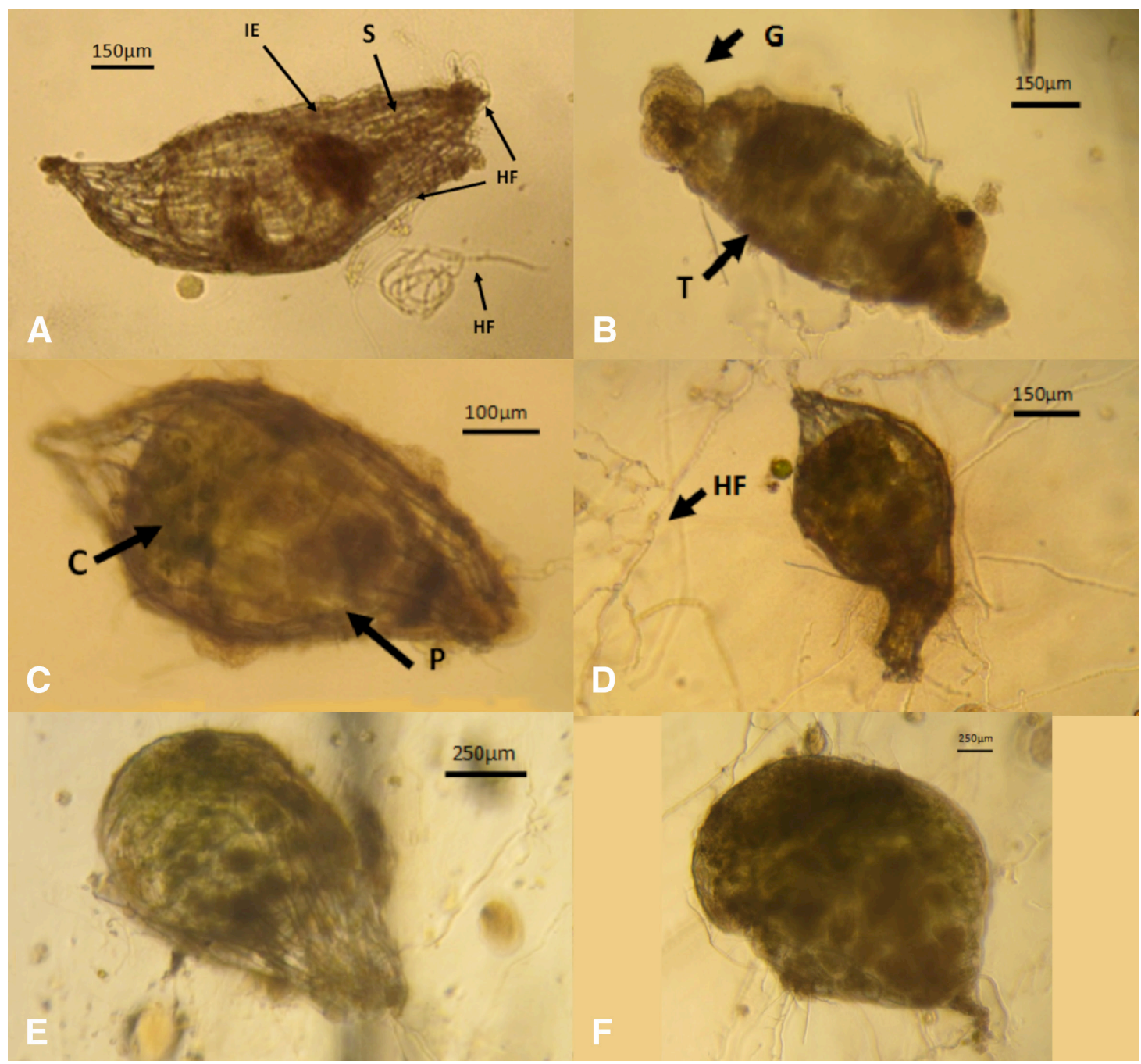

FIgURE 9. Photography of inoculated seeds at different stages in the baitings. A - Can appreciate the hyphae of the endophyte (HF) colonizing the seed through suspensor (S) and inoculating the basal region of the embryo (IE). B - On the surface of the testa $(\mathrm{T})$, can be appreciated a segregated brown substance by the endophyte $(\mathrm{G})$.C - Embryo cells in the chalazal pole (C) are smaller than the pole near the suspensor where we will see the formation of coils (P). D - The external secretions on the surface of the testa have decreased dramatically. E - Rupture of the testa. F - Protocorm.

in vitro conditions. The strain RC062.4EFIM (Fig. 10) generally colonizes the surface of the testa in 10 days and fungal structures appear near the embryo (Fig.11). After 28 days in culture, $98 \%$ of the embryos break the testa, generate protocorms of dark color, have protuberances on their surfaces, showing that the strain had some epiparasitic activity, and after 60 days of culturing the protocorms become necrotic (Fig. 12). This strain cannot colonize the protocorms intracellularly and after 8 days protocorms die. On the other hand, the strain RCRPTC6.3FIM (Fig.13) is unable to infect the seeds, but in 12 days is capable of colonizing the protocorms intracellularly (Fig. 14). However, after 17 days of culture, the protocorms become necrotic. Seeds and protocorms placed in OMA without adding strain (control) survive for 47 days (seeds are only able to break the testa). We agree with many authors that the orchid fungus relationship is not the same under in situ conditions than in vitro (Masuhara et al., 1993; 1994; Taylor \& Bruns, 1999; 


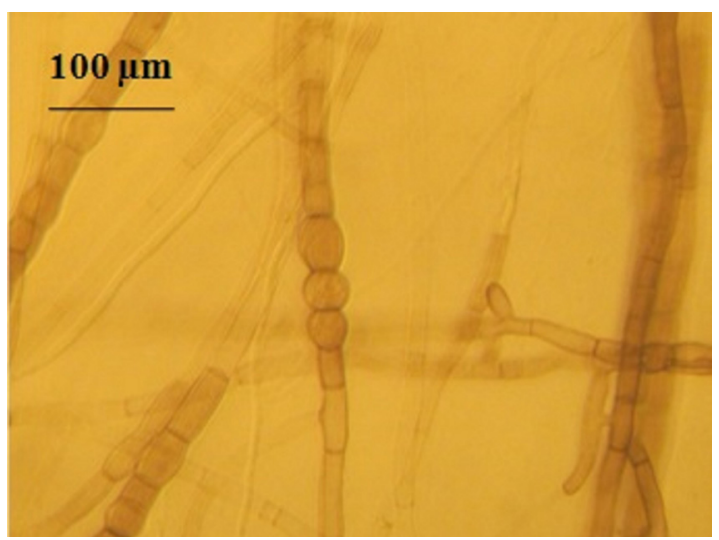

FIGURE 10. The strain RC062.4EFIM.

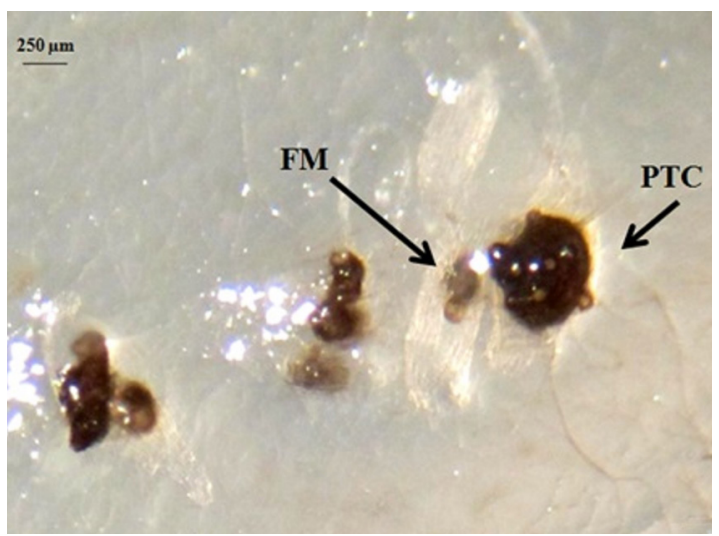

FiguRE 12. Protocorm (PTC) hatched after 60 days with protuberances on its surface, in the image can observer fungal masses (FM) inside of the testa by some embryo that broke.

Taylor et al., 2003; Bidartondo \& Bruns, 2005). The photosynthetic orchids tend to be specific to a single dominant fungus. For epiphytic orchids, these symbionts generally are members of the Tulasnellaceae and Ceratobasidiaceae, while micoheterotrophics orchids associate with wide range of mycobionts (Ma et al., 2002; Otero et al., 2002; McCormick et al., 2004, 2006; Shefferson, 2005; Jolou et al., 2005; Suarez et al., 2006; Dearnaley, 2006). High specificity goes hand in hand with the rarity (or endemic) orchid; however, the dependence on the fungi varies according to gender, species, growth habits, reproductive strategies, physiology and morphology (Brundrett et al., 2003; Stewart \& Kane, 2006; Bonnardeaux et al., 2007), as well as specific microhabitats that allow the establishment (Phillip et al., 2011). Some strains in

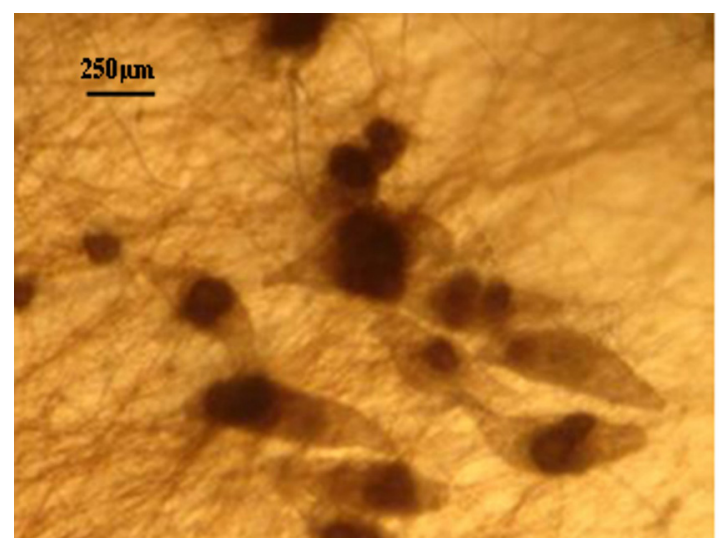

FIGURE 11. Fungal structures of the strain RC062.4EFIM colonized the seeds under in vitro conditions.

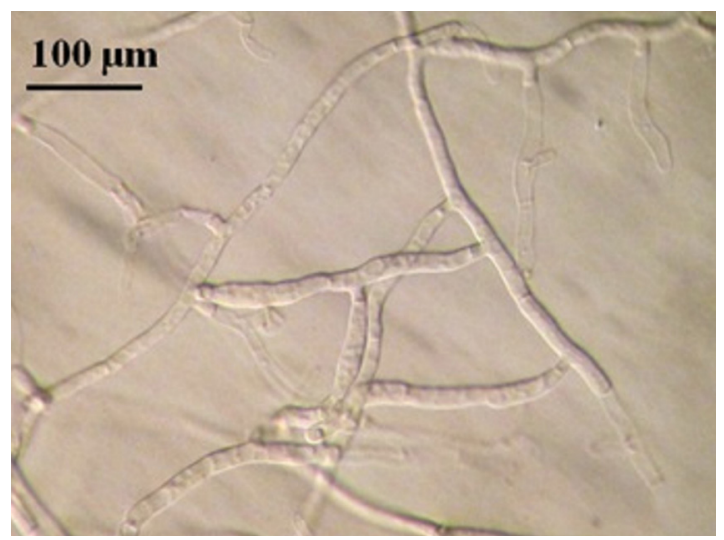

FIGURE 13. The strain RCRPTC6.3FIM.

pure culture are capable of secreting substances via hyphal tip; perhaps under natural conditions hyphal tip works like a "drinking straw" that establishes a biotrophic system during the early stages of seed inoculation, the fungus is able to transform the leachate present in the microhabitat in organic compounds to nourish the seed. To better illustrate this point, according to Stewart and Zettler (2002), the symbiotic germination in vitro, the oat medium is low in nutrients and Rasmussen and Whigham (1998b ) observed no seeds germination of Liparis lilifolia in asymbiotic culture, while the seeds germinated when a mycorrhizal fungus was added to these media, showing some fungus need an external source of nutrients. Perhaps the oat meal agar is not the best option to evaluate whether fungal exudates can stimulate germination; 


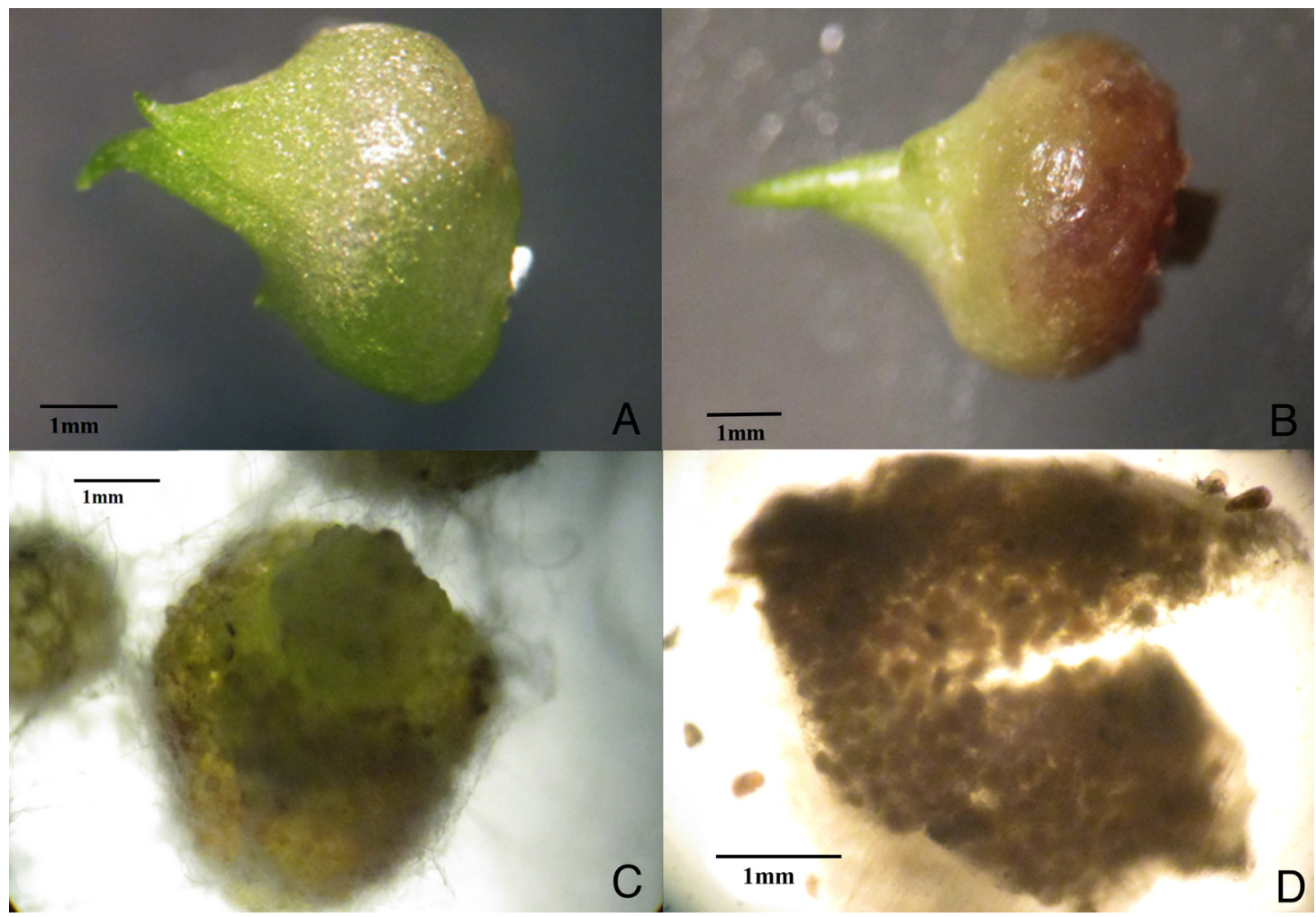

Figure 14. Photography of in vitro inoculated Protocorms. A. Control whit apical shoot. B. Protocorm inoculated basally after 12 day of incubation. C. Protocorm in which can observe fungal hyphae and intracellular coils in the base. D.Tissue section of the basal part of one of the protocorms inoculated, in wich can be observed hyphal coils.

the best option would be to test an alternative culture medium made from bark, or leachate water agar, trying to simulate the natural substrate and saprophytic habitat where germination occurs. We hope that in the future this novel seed baiting technique allows to know the fungal partners and the processes involved during germination and establishment of other species of epiphytic orchids.

AcKnowledgments. The authors would like to thank Dr. Lawrence.W. Zettler for his friendship, suggestions and critical review of the manuscript.

\section{LiteRATURE CITED}

Angle J. S., McGrath S. P., \& Chaney R. L. (1991). New culture medium containing ionic concentrations of nutrients similar to concentrations found in the soil solution. Appl. Environ. Microbiol., 57, $3674-3676$.

Atwood J. T. (1986). The size of the Orchidaceae and the systematic distribution of epiphytic orchids. Selbyana, 9(1), 171-186.

Bidartondo, M. I. \& Bruns, T. D. (2005). On the origins of extreme mycorrhizal specificity in the Monotropoideae (Ericaceae): performance trade-offs during seed germination and seedling development. Mol. Ecol., 14, $1549-1560$.

Bonnardeaux, Y., Brundrett, M., Batty, A., Dixon, K., Koch, J. \& Sivasithamparam, K. (2007). Diversity of mycorrhizal fungi in terrestrial orchids: compatability webs, brief encounters, lasting relationships and alien invasions. Mycol Res., 111, 51-61.

Brundrett, M. C., Scade, A., Batty, L. A., Dixon, W. \& Sivasithamparam, K. (2003). Development of in situ and 
ex situ seed baiting techniques to detect mycorrhizal fungi from terrestrial orchids habitats. Mycol Res., 107, 1210-1220.

Chen, J. Wang, H., \& Guo, S-X. (2012). Isolation and identification of endophytic and mycorrhizal fungi from seeds and roots of Dendrobium (Orchidaceae). Myco., 22, 297-307.

Chia-Chun, H., Fu- Wen, H. \& Chen-Meng, K. (2002). Epiphyte biomass and nutrient capital of a moist subtropical forest in north-eastern Taiwan. J. T. Ecol., 18, 659-670.

Clark, D. L., Nadkarni, N. M. \& Ghozl, H. L. (1988). Growth, net production, litter decomposition, and net nitrogen accumulation by epiphytic bryophytes in a tropical montane forest. Biotrop., 30, 12-23.

Clark, D. L., Nadkarni, N. M. \& Ghozl, H. L. (2005). Retention of inorganic nitrogen by epiphytic bryophytes in a tropical montane forest. Biotrop., 30, 12-23.

Cornelissen, J. H. C., Lang, I. S., Soudzilovskaia, N. A., \& During, H. J. (2007). Comparative cryptogam ecology: A review of Bryophyte and lichen traits that drive biogeochemistry. Ann. Bot., 99, 987-1001.

Cribb, P. J., Kell, R. L., Dixon, W. K. \& Barrett, R. L. (2003). Orchid Conservation: A global perpective. Natural History Publications, Kota Kinabalu, Sabah. pp. 1-24.

DeLuca, T. H., Zackrisson, O. \& Sells-Tedt, A. (2002). Quantifying nitrogen-fixation in feather moss carpets of boreal forest. Nat., 419, 917-920.

Dumbrell, A. J., Ashton, P. D., Aziz, N., Feng, G., Nelson, M., Dytham, C., Fitter, A.H., \& Helgason, T. (2010). Distinct seasonal assembleges of arbuscular mycorrhizal fungi revealed by massively parallel pyrosequencing. New Phytol., 190, 794-804.

Jolou, T., Burghardt, B., Gebauer, G., Berveiller, D., Damesin, C. \& Selosse, M.-A. (2005). Mixotrophy in orchids: insights from a comparative study of green individuals and nonphotosynthetic individuals of Cephalanthera damasonium. New Phytol., 166, 639-653.

Lugo, A. M. \& Cabello, M. N. (2002). Native arbuscular mycorrhizal fungi (AMF) from mountain grassland (Córdoba, Argentina) I. Seasonal variation of fungal spore diversity. Mycol., 94, 579-586.

Ma, M., Tan, T. K. \& Wong, S. M. (2002). Identification and molecular phylogeny of Epulorhiza isolates from tropical orchids. Mycol Res., 107, 1041-1049.

Masuhara, G., Katsuya, K. \& Yamagucki, K. (1993). Potential for symbiosis of Rhizoctonia solani and binucleate Rhizoctonia with seeds of Spiranthes amoena var. amoena in vitro. Mycol Res., 97, 746-752.

Masuhara, G. \& Katsuya, K. (1994). In situ and in vitro specificity between Rhizoctonia spp. and Spiranthes sinensis (Persoon) Ames. var. amoena (M. Biebertsien ) Hara (Orchidaceae). New Phytol., 127, 711-718.

McCormick, M. K., Whigham, D. F. \& O’Neill, J. (2004). Mycorrhizal diversity in photosynthetic terrestrial orchids. New Phytol., 163, 425-438

McCormick, M. K., Whigham, D. F., Sloan, D. O’Malley, K., \& Hodkinson, B. (2006). Orchid-fungus fidelity: a marriage meant to last? Ecol., 87, 903-911.

Nontachaiyapoom, S., Sasirat, S., \& Manoch, L. (2010). Symbiotic seed germination of Grammatophyllum speciosum Blume and Dendrobium draconis Rchb. f., native orchids of Thailand. Sci. Hort., 130, 303-308.

Otero, J. T., Ackerman, J. D. \& Bayman, P. (2002). Diversity and host specificity of endophytic Rhizotonia-like fungi from tropical orchids. Am. J. Bot., 89, 1852-1858.

Otero, J. T., Flanagan, S. N., Allen Herre, E., Ackerman, D. J. \& Bayman, P. (2007). Widespread mycorrhizal specificity correlates to mycorrhyzal function in the neotropical, epiphytic orchid Ionopsis utricularioides (Orchidaceae). Am. J. Bot., 94(12), 1944-50.

Pereira, O. L., Rollemberg, C. L., Borges, A. C., Matsuokae, K. \& Kasuya, M. C. M. (2003). Epulorhiza epiphytica sp. nov. isolatated from mycorrhizal roots of epiphytic orchids in Brazil. Mycos, 44, 153-155.

Pereira, O. L., Kasuya, M. C. M., Rollemberg, C. L. \& Borges, A. C. (2005). In vitro seed Germination of Oncidium flexosum (Orchidaceae) by Rhizoctonia-like Mycorrhizal fungi. R. Bras. Ci. Solo, 29, 199-206.

Phillips, R. D., Barret, D., Dixon, W. K. \& Hopper, D. S. (2011). Do mycorrhizal symbioses cause rarity in orchids?. J. Ecol., 99, 858-869. 
Rai, A. N. Soderback, E. \& Bergman, B. (2000). Cyanobacterium-plant symbioses. New Phytol, 147, 449-481.

Rasmussen, H. N. \& Whigham, D. F. (1993). Seed ecology of dust seeds in situ: a new study technique and its application in terrestrial orchids. Am. J. Bot., 80, 1374-1378.

Rasmussen, H. N. \& Whigham, D. F. (1998a). Importance of woody debris in seed germination of Tipularia discolor (Orchidaceae). Am. J. Bot., 85, 829-834.

Rasmussen, H. N. \& Whigham, D. F. (1998b). The underground phase: a special challenge in studies of terrestrial orchids populations. Bot. J. Linnean Soc., 126, 49-64.

Rasmussen H. N. (2002). Recent developments in the study of orchid mycorrhiza. Plant and soil., 244, 149-163.

Shefferson, R. P., Weiß, M., Kull, T. \& Taylor, D. L. (2005). High specificity generally characterises mycorrhizal association in rare lady's slipper orchids, genus Cypripedium. Mol. Ecol., 14, 613-626.

Stewart, S. L. \& Zettler, L. W. (2002). Symbiotic germination of three semi-aquatic rein orchids (Habenaria repens, $H$. quinqueseta, H. macroceratitis) from Florida. Aquat. Bot., 72, 25-35.

Stewart, S. L. \& Kane, M. E. (2006). Symbiotic seed germination of Habenaria macroceratitis (Orchidaceae), a rare Florida terrestrial orchid. Pl. Cell Tissue Organ Cult., 86, 159-167.

Suarez, J. P., Weibßb, M., Abeleb, A., Garnica, S., Oberwinkler, F. \& Kottke, I. (2006). Diverse tulasnelloid fungi form mycorrhizas with epiphytic orchids in an Andean cloud forest. Mycol Res., 110, 1257-1270.

Taylor, D. L. \& Bruns, T. D. (1999). Population, habitat and genetic correlates of mycorrhizal specialization in the 'cheating' orchids Corallorhiza maculata and C. mertensiana. Mol. Ecol., 8, 1719-1732.

Taylor, D. L., Bruns, T. D., Szaro, T. M. \& Hodges, S. A. (2003). Divergence in mycorrhizal specialization within Hexalectris spicata (Orchidaceae), a nonphotosynthetic desert orchid. Am. J. Bot., 90, 1168-1179.

Turetsky, M. R. (2003). The role of Bryophytes in Carbon and Nitrogen Cycling. The Bryol., 106, 395-409.

Van Waes, J. M. \& Debergh, P. C. (1986). Adaptation of the tetrazolium method for testing the seed viability, and scanning electron microscopy study of some Western European orchids. Phys. Plant., 66, 435-442.

Yoder, J. A., Zettler, L. W. \& Stewart, S. L. (2000). Water requirements of terrestrial and epiphytic orchid seeds and seedlings, and evidence for water uptake by means of mycotrophy. Pl. Science, 156, 145-150.

Zettler, L. W, Burkhead, J. C. \& Marshall, J. A. (1999). Use of a mycorrhizal fungus from Epidendrum conopseum to propagate Encyclia tampensis from seed in vitro. Lindleyana, 14, 102-105.

Zettler, L. W., Corey, L. L., Richardson, L. W., Ross, A. Y. \& Moller-Jacobs, L. (2011). Protocorms of an epiphytic orchid, (Epidendrum amphistomum A. Richard) recovered in situ, and subsequent identification of associated mycorrhizal fungi using molecular markers. E. J. Enviro. Sc., 1, 108-114.

Zi, X-M., Sheng, C-L., Goodale, U. M. Shao, S-Ch., \& Gao, J-Y. (2014). In situ seed baiting to isolate germinationenhancing fungi for an epiphytic orchid, Dendrobium aphyllum (Orchidaceae). Myc., 10, 565-572. 